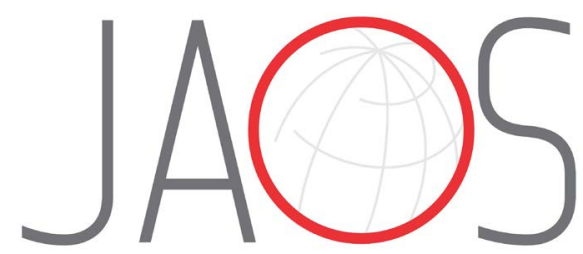

JOURNAL OF APPLIED ORAL SCIENCE

\title{
Increased whitening efficacy and reduced cytotoxicity are achieved by the chemical activation of a highly concentrated hydrogen peroxide bleaching gel
}

\section{Abstract}

Diana Gabriela SOARES ${ }^{1}$

Natália MARCOMINI ${ }^{2}$

Carla Caroline de Oliveira DUQUE ${ }^{3}$

Ester Alves Ferreira BORDINI ${ }^{3}$

Uxua Ortecho ZUTA ${ }^{3}$

Fernanda Gonçalves BASSO ${ }^{4}$

Josimeri HEBLING ${ }^{5}$

Carlos Alberto de Souza COSTA ${ }^{4}$
Submitted: August 2, 2018 Modification: October 29, 2018 Accepted: November 28, 2018

Corresponding address: Carlos Alberto de Souza Costa Departamento de Fisiologia e Patologia Faculdade de Odontologia de Araraquara - UNESP. Rua Humaitá, 1680, Centro - Araraquara SP- 14801-903 - Brasil .

Phone: +55-16-3301-6477/Fax: 55-16-3301-6488. e-mail: casouzac@foar.unesp.br
Objective: This study was designed for the chemical activation of a $35 \%$ hydrogen peroxide $\left(\mathrm{H}_{2} \mathrm{O}_{2}\right)$ bleaching gel to increase its whitening effectiveness and reduce its toxicity. Methodology: First, the bleaching gel - associated or not with ferrous sulfate (FS), manganese chloride (MC), peroxidase (PR), or catalase (CT) - was applied (3x $15 \mathrm{~min}$ ) to enamel/dentin discs adapted to artificial pulp chambers. Then, odontoblast-like MDPC-23 cells were exposed for $1 \mathrm{~h}$ to the extracts (culture medium + components released from the product), for the assessment of viability (MTT assay) and oxidative stress $\left(\mathrm{H}_{2}\right.$ DCFDA). Residual $\mathrm{H}_{2} \mathrm{O}_{2}$ and bleaching effectiveness $(\Delta \mathrm{E})$ were also evaluated. Data were analyzed with one-way ANOVA complemented with Tukey's test $(n=8 . p<0.05)$. Results: All chemically activated groups minimized MDPC-23 oxidative stress generation; however, significantly higher cell viability was detected for $M C, P R$, and $C T$ than for plain $35 \% \mathrm{H}_{2} \mathrm{O}_{2}$ gel. Nevertheless, FS, MC, PR, and CT reduced the amount of residual $\mathrm{H}_{2} \mathrm{O}_{2}$ and increased bleaching effectiveness. Conclusion: Chemical activation of $35 \%$ $\mathrm{H}_{2} \mathrm{O}_{2}$ gel with $\mathrm{MC}, \mathrm{PR}$, and $\mathrm{CT}$ minimized residual $\mathrm{H}_{2} \mathrm{O}_{2}$ and pulp cell toxicity; but PR duplicated the whitening potential of the bleaching gel after a single 45-minute session.

Keywords: Tooth bleaching. Dental pulp. Cytotoxicity. Odontoblasts.
'Universidade de São Paulo, Faculdade de Odontologia de Bauru, Departamento de Dentística, Endodontia e Materiais Odontológicos, Bauru, São Paulo, Brasil.

2Universidade Estadual Paulista - UNESP, Faculdade de Odontologia de Araraquara, Departamento de Dentística Restauradora, Araraquara, São Paulo, Brasil.

${ }^{3}$ Universidade Estadual Paulista - UNESP, Faculdade de Odontologia de Araraquara, Departamento de Materiais Dentários e Prótese, Araraquara, São Paulo, Brasil.

${ }^{4}$ Universidade Estadual Paulista - UNESP, Faculdade de Odontologia de Araraquara, Departamento de Fisiologia e Patologia, Araraquara, São Paulo, Brasil.

${ }^{5}$ Universidade Estadual Paulista - UNESP, Faculdade de Odontologia de Araraquara, Departamento de Clínica Infantil, Araraquara, São Paulo, Brasil. 


\section{Introduction}

Hydrogen peroxide $\left(\mathrm{H}_{2} \mathrm{O}_{2}\right)$ is found in high concentrations in bleaching gels widely used for inoffice tooth-bleaching therapies. ${ }^{1}$ Whitening outcome is believed to be a consequence of $\mathrm{H}_{2} \mathrm{O}_{2}$ decomposition, which generates free radicals that interact with chromophores present in dentin substrate. ${ }^{2}$ Instead of being considered a strong oxidant agent, $\mathrm{H}_{2} \mathrm{O}_{2}$ is the reactive oxygen species (ROS) with the lowest oxidative potential ${ }^{3}$. Therefore, to achieve effective dental color alteration in short periods, highly concentrated $\mathrm{H}_{2} \mathrm{O}_{2}$ bleaching gels (35-40\%) have been traditionally used for professional tooth-bleaching. ${ }^{1}$ However, many studies have shown that such esthetic therapy allows diffusion of high amounts of $\mathrm{H}_{2} \mathrm{O}_{2}$ through enamel and dentin, ${ }^{4,5}$ causing in vitro ${ }^{6-11}$ and in vivo ${ }^{12-15}$ toxicity to pulp cells. Therefore, the "non-reacted $\mathrm{H}_{2} \mathrm{O}_{2}$ " has been considered the main pathway for bleaching-induced tooth sensitivity, claimed by $80-100 \%$ of patients undergoing professional tooth-bleaching performed with high-concentrated gels. ${ }^{16,17}$

The cell toxicity mechanism mediated by bleaching gels on pulp cells has been correlated with two main pathways: (1) $\mathrm{H}_{2} \mathrm{O}_{2}$ arising in the pulp chamber during the bleaching procedure can diffuse through the cell membrane, followed by dissociation into free radicals on cytoplasm, causing a pathologic stress oxidative condition, lipid peroxidation, and necrosis; and (2) free radicals in the extracellular environment after $\mathrm{H}_{2} \mathrm{O}_{2}$ dissociation cause direct damage to cell membranes, leading to cell death by necrosis. ${ }^{18}$ The establishment of an inflammatory reaction and necrotic areas in pulp tissue of teeth subjected to professional bleaching has been observed in several in vivo studies. ${ }^{12-15,19-21}$ Recent demonstrations show $\mathrm{H}_{2} \mathrm{O}_{2}$ from bleaching gels induces pro-inflammatory cytokine release by pulp cells, negatively influencing their long-term regenerative potential. $8,11,14,15,22$

Therefore, many alternative therapies have been proposed to increase the biocompatibility of in-office bleaching therapy with the pulp-dentin complex, mainly aimed at reducing the amount of $\mathrm{H}_{2} \mathrm{O}_{2}$ capable of reaching pulp cells. ${ }^{18}$ Several authors have reported that reducing the $\mathrm{H}_{2} \mathrm{O}_{2}$ concentration in bleaching gels and the period of contact of these dental products with enamel may decrease the in vitro and in vivo toxicity caused by these esthetic therapies. ${ }^{7-10,12-15,22}$ However, additional sessions are needed to achieve bleaching outcomes similar to those of traditional therapies. ${ }^{7,10,23}$ Increasing the degradation rate of $\mathrm{H}_{2} \mathrm{O}_{2}$ has also been proposed as an alternative to minimizing residual $\mathrm{H}_{2} \mathrm{O}_{2}$ diffusion through enamel and dentin. ${ }^{24-29}$ Indeed, when manganese and iron-rich molecules are used to induce $\mathrm{H}_{2} \mathrm{O}_{2}$ decomposition into free radicals with Fenton and Fenton-like reactions, the $\mathrm{H}_{2} \mathrm{O}_{2}$ amount that reaches the pulp chamber in vitro is intensely reduced ${ }^{24,27}$. Duque, et al. ${ }^{29}$ (2014) also demonstrated that association of $35 \% \mathrm{H}_{2} \mathrm{O}_{2}$ with ferrous sulfate enhanced tooth-bleaching effectiveness and reduced $\mathrm{H}_{2} \mathrm{O}_{2}$ diffusion through enamel and dentin; but no significant minimization of odontoblast-like cell cytotoxicity was detected. Other studies have reported that plant extracts containing catalase and peroxidase enzymes, which can induce $\mathrm{H}_{2} \mathrm{O}_{2}$ degradation into free radicals, also have the potential to promote positive effects on bleaching effectiveness. ${ }^{25,27}$

Nevertheless, none of these studies compared the biological and esthetic effects of different substances capable of enhancing free radical release from $\mathrm{H}_{2} \mathrm{O}_{2}$ to select those that can be used as chemical activators of tooth-bleaching gels. Therefore, the aim was to evaluate the potential of Fenton's reagents (ferrous sulfate and manganese chloride) and purified oxidoreductase enzymes (peroxidase and catalase) as chemical activators of a $35 \% \mathrm{H}_{2} \mathrm{O}_{2}$ bleaching gel, on the trans-enamel/trans-dentinal diffusion of $\mathrm{H}_{2} \mathrm{O}_{2}$, pulp cell cytotoxicity, and bleaching effectiveness. Null hypothesis is that chemical activation has no effect on bleaching effectiveness, diffusion of residual $\mathrm{H}_{2} \mathrm{O}_{2}$, oxidative stress generation and cell viability reduction mediated by the $35 \% \mathrm{H}_{2} \mathrm{O}_{2}$ bleaching gel on odontoblast-like cells.

\section{Methodology}

\section{Enamel/dentin discs}

Enamel/dentin discs (from 24- to 30-monthold bullocks), measuring $5.6 \mathrm{~mm}$ in diameter and $3.5 \mathrm{~mm}$ in thickness, were obtained as previously described. ${ }^{29}$ Enamel surface was cleaned with pumice stone solution under low speed handpiece (Dabi Atlante, Ribeirão Preto, SP, Brazil), and then evaluated with stereoscopic magnifying glass (Olympus 5ZX\&, Olympus, São Paulo, SP, Brazil) to eliminate those samples with enamel defects, such as the presence of superficial cracks or hypoplasia. Dentin surfaces 
were cleaned with $0.5 \mathrm{M}$ ethylenediaminetetraacetic acid solution (EDTA; Sigma-Aldrich, St. Louis, MO, USA), $\mathrm{pH} 7.2$, for $30 \mathrm{~s}$, to remove the smear layer, and the enamel surfaces were cleaned with a solution of pumice stone and distilled water at low speed.

\section{Bleaching procedure}

After selecting the discs with sound enamel and standardized thickness at $3.5 \mathrm{~mm}$, they were randomly distributed into the following groups: NC (negative control) - no treatment was performed on enamel; HP - 35\% $\mathrm{H}_{2} \mathrm{O}_{2}$ gel (Whiteness HP 35\%; FGM, Joinville, SC, Brazil); $\mathrm{HP}+\mathrm{FS}-35 \% \mathrm{H}_{2} \mathrm{O}_{2}$ gel (Whiteness HP 35\%; FGM) associated with ferrous sulfate $\left(\mathrm{FeSO}_{4} \cdot 7 \mathrm{H}_{2} \mathrm{O}\right.$, chunks, $\geq 99 \%$ trace metals basis, Sigma-Aldrich); $\mathrm{HP}+\mathrm{MC}-35 \% \mathrm{H}_{2} \mathrm{O}_{2}$ gel (Whiteness HP 35\%; FGM) associated with manganese chloride $\left(\mathrm{MnCl}_{2}\right.$, powder and chunks, $\geq 99 \%$ trace metals basis, Sigma-Aldrich); $\mathrm{HP}+\mathrm{PR}-35 \% \mathrm{H}_{2} \mathrm{O}_{2}$ gel (Whiteness HP 35\%; FGM) associated with horseradish peroxidase enzyme (type VI-A, lyophilized powder, 950-2000 units/mg solid, Sigma-Aldrich); and $\mathrm{HP}+\mathrm{CT}-35 \% \mathrm{H}_{2} \mathrm{O}_{2}$ gel (Whiteness HP 35\%; FGM) associated with catalase from bovine liver enzyme (powder, 2,000-5,000 units/mg protein, Sigma-Aldrich). For the chemically activated groups $(\mathrm{HP}+\mathrm{FS}, \mathrm{HP}+\mathrm{MC}, \mathrm{HP}+\mathrm{PR}$, and $\mathrm{HP}+\mathrm{CT}), 1 \mathrm{mg}$ of activators was incorporated into one drop of thickening agent ( $50 \mathrm{~mL}$; Whiteness HP 35\%; FGM) by manual mixing. ${ }^{24-26,29}$ Then, three drops of the $\mathrm{H}_{2} \mathrm{O}_{2}$ liquid phase $(100 \mathrm{~mL}$ ) were added, and the product was mixed for $15 \mathrm{~s}$. This procedure was performed immediately before each application of the product. In the HP group, the same procedure was performed but no chemical substance was incorporated. The manipulation of the bleaching gel ( 1 drop of thickening per 3 drops of $\mathrm{H}_{2} \mathrm{O}_{2}$ ) was based on the manufacturer's instructions (FGM). In total, three 15-minute applications were performed in all bleached groups, and a $40-\mathrm{mL}$ volume of bleaching gels was applied to enamel at each 15-minute application, via a pipette coupled with a capillary piston tip (Microman E, Gilson, Middelton, WI, USA), which allows standardized pipetting of viscous liquid. Digital images were taken at a $45 \mathrm{~cm}$ distance from the specimens, with a DSLR camera (Nikon D3300; F 22, ISO 200, speed 180; Melville, NY, USA) coupled with macro lenses ( $90 \mathrm{~mm}$; F2.8. Tamron, Colonia, Italy) and a circular flash (EM-140DG Macro flash, speed 1/16; Sigma Corporation of America, Ronkonkoma, NY, USA) to observe the reaction of the bleaching gel with the chemical activators during the 15-minute application time. The $\mathrm{pH}$ was measured with a bench top pH meter (HI2221 Calibration Check pH/ ORP Meter, Hanna Instruments, Woonsocket, Rhode Island, NE, USA), coupled with a microprobe (HI1131P General Purpose pH Electrode, Hanna Instruments). The bleaching gels were manipulated in a $1.5 \mathrm{~mL}$ tube, and the probe was submersed into the material. The $\mathrm{pH}$ was checked after $0.5,5,10$, and $15 \mathrm{~min}$. A total of 4 samples per group was manipulated for this analysis.

\section{Trans-enamel and trans-dentinal cytotoxicity}

Enamel/dentin discs were adapted to artificial pulp chambers (APC), as previously described. ${ }^{29}$ The APC/disc sets (sterilized in ethylene oxide) were placed in 24-well plates with dentin in contact with $1 \mathrm{~mL}$ of DMEM (Dulbecco's Modified Eagle Medium; supplemented with $100 \mathrm{IU} / \mathrm{mL}$ penicillin, $100 \mathrm{mg} / \mathrm{mL}$ streptomycin, and $2 \mathrm{mmol} / \mathrm{L}$ glutamine; Gibco, Grand Island, NY, USA). Enamel remained exposed to receive the treatments according to each group. Immediately after the bleaching procedure, the culture medium (extract) was collected and distributed into 100-mL aliquots, which were applied for $1 \mathrm{~h}$ to odontoblast-like MDPC- 23 cells previously seeded in an $80 \%$ confluence pattern $\left[1 \times 10^{4}\right.$ cells/96-well plates in DMEM plus $10 \%$ fetal bovine serum (FBS), for $24 \mathrm{~h}$ at $37^{\circ} \mathrm{C}$ and $\left.5 \% \mathrm{CO}_{2}\right]$. Cell viability was assessed by incubation of the cells for $4 \mathrm{~h}$ in DMEM without FBS (Gibco) supplemented (10:1) with $5 \mathrm{mg} / \mathrm{mL}$ MTT solution (Sigma-Aldrich) at $37^{\circ} \mathrm{C}$ and $5 \% \mathrm{CO}_{2}$. The absorbance of formazan crystals in the viable cells was read ( 570 nm; Synergy H1, BioTek, Winooski, VT, USA), and the mean absorbance of the NC group was considered $100 \%$ of cell viability $(n=8)$. Oxidative stress was evaluated in cells pre-treated with fluorescence probe carboxy- $\mathrm{H}_{2}$ DCFDA (5 mM; Invitrogen, Carlsbad, CA, USA) $(n=8)$, and then exposed for $1 \mathrm{~h}$ to the extracts. After this period, the fluorescence intensity was monitored at $59 \mathrm{~nm}$ excitation and $517 \mathrm{~nm}$ emission (Synergy $\mathrm{H} 1$, BioTek), and the fold increases were calculated after normalization with the NC group.

\section{Quantification of residual $\mathrm{H}_{2} \mathrm{O}_{2}$}

A $100-\mu \mathrm{L}$ aliquot of the extract collected from the same samples of trans-enamel and trans-dentinal cytotoxicity assay $(n=8)$ was transferred to tubes containing $900 \mathrm{~mL}$ of acetate buffer solution (2 $\mathrm{mol} / \mathrm{L}, \mathrm{pH} 4.5$ ), to avoid $\mathrm{H}_{2} \mathrm{O}_{2}$ degradation. Then, $500-\mu \mathrm{L}$ of buffer solution plus extract was transferred 
to experimental tubes to react with leuco crystal violet $(0.5 \mathrm{mg} / \mathrm{mL}$; Sigma-Aldrich) and horseradish peroxidase enzyme (1 mg/mL; Sigma-Aldrich). The final volume of reaction was adjusted to $3 \mathrm{~mL}$ with distilled water, and the optical density of the solutions was measured at $600 \mathrm{~nm}$ wavelength (Synergy H1, BioTek). To estimate the effects of chemical activators on $\mathrm{H}_{2} \mathrm{O}_{2}$ diffusion, the HP group was considered $100 \%$ of $\mathrm{H}_{2} \mathrm{O}_{2}$ diffusion, and diffusion percentages for chemically activated groups were calculated based on this parameter.

\section{Color alteration measurement}

For this analysis, the discs were subjected to staining with black tea to standardize the baseline color $(n=8) .{ }^{29}$ This procedure was performed to randomly distribute specimens with similar $L^{*}$ and $b^{*}$ values (CIE $L^{*} a * b *$ system) among the control and experimental groups, obtaining standardized samples. Darkened samples were used to verify the potential of the different formulations to fasten the whitening outcome compared with the gel with no chemical supplementation.

Specimens were kept in $100 \%$ humidity to standardize the hydration pattern. For that, the discs were placed at the bottom of wells of 24-well plates in a way that dentin was maintained in contact with a cotton pellet embedded with deionized water, and the enamel was covered with a cotton pellet embedded in artificial saliva solution. ${ }^{10,23}$ The plates were kept in incubator for $72 \mathrm{~h}$, at $37^{\circ} \mathrm{C}$ (Orion 515, Fanen, São Paulo, SP, Brazil). A color readout was then used to obtain baseline (BS) values for each disc. To be read, the discs were positioned in a white silicone matrix, leaving only the enamel surface exposed. A portable UV-VIS spectrophotometer with $4 \mathrm{~mm}$ aperture (Color Guide 45/0; BYK-Gardner GmbH, Geretsried, BAV, Germany) was positioned over the center of the $5.6 \mathrm{~mm}$ diameter disc, so that only the surface of the sample was read with no interference of the background color. The samples were read in sequence by the same operator. A total of three sequential readings was performed to eliminate bias from spectrophotometer positioning onto the sample.

Bleaching protocol was performed on enamel surfaces, after each enamel was washed with deionized water and dried with filter paper. The specimens were incubated in $100 \%$ humidity for $72 \mathrm{~h}$ to allow for rehydration, and a post-bleaching (PS) color readout was obtained. Values of $L^{*} a * b *$ were recorded to obtain $\Delta \mathrm{L}, \Delta \mathrm{a}$, and $\Delta \mathrm{b}$ values for each sample by the following equation: $\Delta(\mathrm{L}$, a or $\mathrm{b})=\mathrm{PS}$ value $\left(\mathrm{L}^{*}, \mathrm{a}^{*}\right.$, or $\left.b^{*}\right)$ - BS value ( $L^{*}, a^{*}$, or $\left.b^{*}\right)$. Overall color change of each specimen, expressed as $\Delta \mathrm{E}$, was calculated according to the equation $\Delta \mathrm{E}=\left[(\Delta \mathrm{L})^{2}+(\Delta \mathrm{a})^{2}+(\Delta \mathrm{b})^{2}\right]^{1 / 2}$.

\section{Statistical analysis}

Sample size was calculated with DDS Research (Sample Size Calculator, average, two samples, $a=5 \% ; b=95 \%$, and eight samples per group were stablished for each assay. Percentage of cell viability (MTT assay) (NC versus HP) and DE (NC versus HP) were used as parameters. Power calculation analyses were also performed by DDS Research (Statistical Power Calculator, average, two sample, two-tail test, $a=5 \%$ ) at the end of the experiment, showing $100 \%$ statistical power for each evaluation. Two independent experiments were performed for each assay. Data were compiled and analyzed by Kolmogorov-Smirnov and Levene tests. Since normal data were obtained, one-way ANOVA and Tukey's test were used for cell viability, as well as $\mathrm{H}_{2} \mathrm{O}_{2}$ diffusion, oxidative stress, $\mathrm{DE}, \mathrm{DL}, \mathrm{Da}$, and $\mathrm{Db}$ analysis. Data of $\mathrm{pH}$ measurement were analyzed with repeated measure two-way ANOVA and Dunnet's test to compare $\mathrm{pH}$ values at each timepoint with those from HP group. All statistical analyses were carried out at a significance level of $5 \%$.

\section{Results}

\section{Chemical activation characteristics}

Reaction immediately before manipulation and after 5,10 , and 15 minutes on tooth surfaces can be observed in Figure 1a. Bubbles were observed in all chemically activated groups and deposition of brown sub-products was detected only in groups $\mathrm{HP}+\mathrm{MC}$ and $\mathrm{HP}+\mathrm{FS}$. $\mathrm{pH}$ values of the bleaching gels at each timepoint and the statistical analysis through time can be observed in Figure $1 \mathrm{~b}$. The statistical analysis through time can be observed in Figure 1b. Significant increase in the $\mathrm{pH}$ compared with HP group was detected for $\mathrm{HP}+\mathrm{FS}$ at $5 \mathrm{~min}$ and for $\mathrm{HP}+\mathrm{MC}$ at $0.5 \mathrm{~min}$. The enzymes peroxidase and catalase had insignificant influence on the $\mathrm{pH}$ of the $35 \% \mathrm{H}_{2} \mathrm{O}_{2}$ gel.

\section{Biologic assays}

Considerable cell viability reduction was observed 
(a)

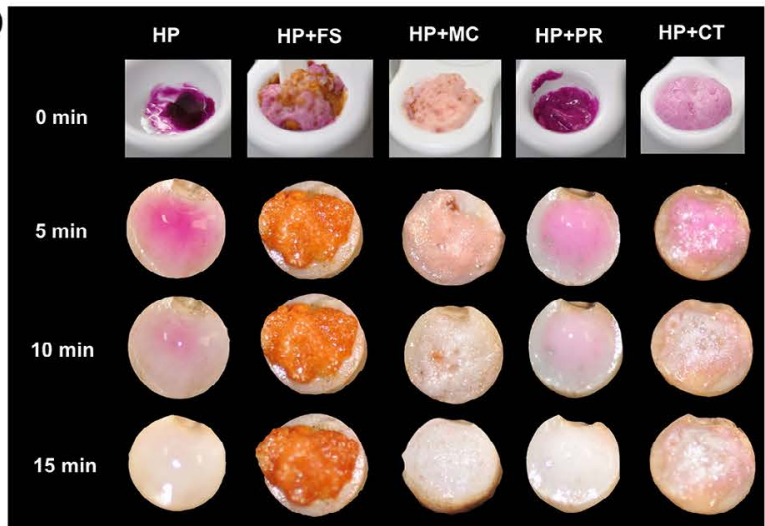

(b)

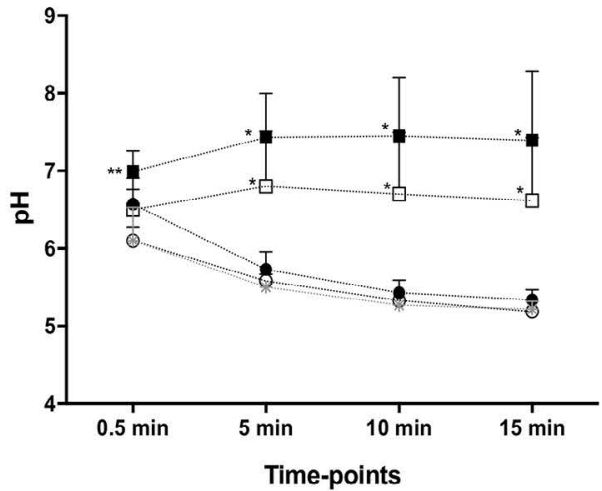

*-. $\mathrm{HP}$

$\because \mathrm{HP}+\mathrm{FS}$

-... $\mathrm{HP}+\mathrm{MC}$

-.). HP+PR

-.. $\mathrm{HP}+\mathrm{CT}$

${ }^{*} p<0.001$
$* * p=0.02$

Figure 1- (a) Representative digital images of bleaching gel reaction in the presence or not of chemical activators, immediately after manipulation ( $0 \mathrm{~min}$ ) and after 5,10 , and $15 \mathrm{~min}$ on enamel/dentin discs. Note the bubbles in $\mathrm{HP}+\mathrm{FS}, \mathrm{HP}+\mathrm{MC}$, and $\mathrm{HP}+\mathrm{CT}$ groups. Deposition of brown sub-products can be observed in groups HP+FS and HP+MC. (b) Graph representative of mean (standard deviation) values of $\mathrm{pH}$ for the bleaching gels at $0.5,5,10$, and 15 min. Asterisks indicates significant difference with the HP group (repeated measures Two-way ANOVA/Dunnet's test, $p<0.05$ )

(a)

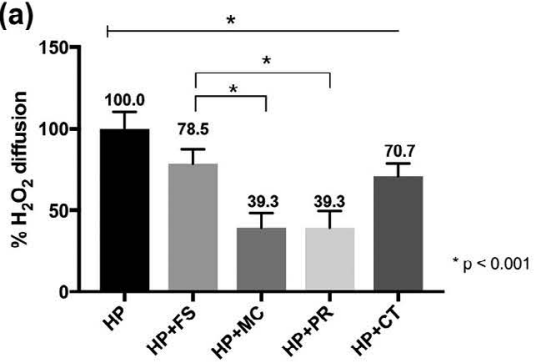

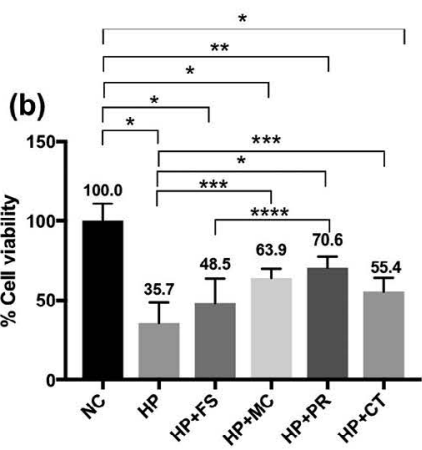

(c)

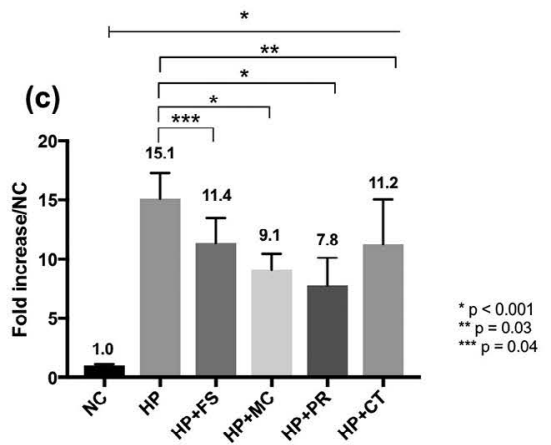

Figure 2- (a), (b), and (c) Bar graph of mean values (standard deviation) of cell viability percentages (MTT assay), fold increase in carboxy-H2DCFDA fluorescence (oxidative stress), and residual $\mathrm{H}_{2} \mathrm{O}_{2}$ percentages (violet leuco-crystal/peroxidase assay), respectively. Numbers are mean values for each assay. —demonstrates the comparison between groups from the start to end points under the line; — demonstrates the comparison between groups; asterisk indicates significant difference (one-way ANOVA/Tukey's test; $p<0.05$ )

for all bleached groups compared with NC; however, cell viability higher than that of the HP group was determined for the $\mathrm{HP}+\mathrm{MC}, \mathrm{HP}+\mathrm{PR}$, and $\mathrm{HP}+\mathrm{CT}$ groups, with $\mathrm{HP}+\mathrm{PR}$ featuring the greatest value (Figure 2a). Increased oxidative stress was detected for all groups related to NC; but all bleached groups associated with chemical activators featured oxidative stress substantially lower than that found in the HP group (Figure $2 b$ ).

\section{Residual $\mathrm{H}_{2} \mathrm{O}_{2}$ quantification}

Reductions in $\mathrm{H}_{2} \mathrm{O}_{2}$ diffusion occurred for those extracts obtained from bleached groups associated with chemical activators compared with plain $\mathrm{H}_{2} \mathrm{O}_{2}$ gel (HP group). The HP+MC and HP+PR groups featured significantly lower $\mathrm{H}_{2} \mathrm{O}_{2}$ amounts on extracts compared with the other groups (Figure 2c).

\section{Bleaching effectiveness}

All bleached groups presented notably higher DE values than the NC group. HP+PR featured the highest
DE value, which was significantly different from that of the other groups (Figure 3a). All the bleached groups promoted significant increase in DL and decrease in Db compared with NC group; nevertheless, only HP+PR featured significant differences with HP group for both parameters. Considerable reduction in Da related to NC group was detected for HP+PR and HP+MC groups.

\section{Discussion}

Catalyzed $\mathrm{H}_{2} \mathrm{O}_{2}$ propagation has been used to increase the oxidative potential of $\mathrm{H}_{2} \mathrm{O}_{2}$, that, in turn, eliminates organic contaminants from aquifers and soil ${ }^{3}$. Depending on environmental conditions, $\mathrm{H}_{2} \mathrm{O}_{2}$ may be dissociated into different molecules, releasing oxygen $\left(\mathrm{O}_{2}\right)$, water $\left(\mathrm{H}_{2} \mathrm{O}\right)$, and highly reactive free radicals, such as hydroxyl (HO), perihydroxyl $\left(\mathrm{HO}_{2}{ }^{\prime}\right)$, and superoxide $\left(\mathrm{O}_{2}{ }^{\prime}\right)$ radicals. ${ }^{30}$ Following the same catalytic mechanism, the aim was to reduce the amount of residual $\mathrm{H}_{2} \mathrm{O}_{2}$ on tooth- 

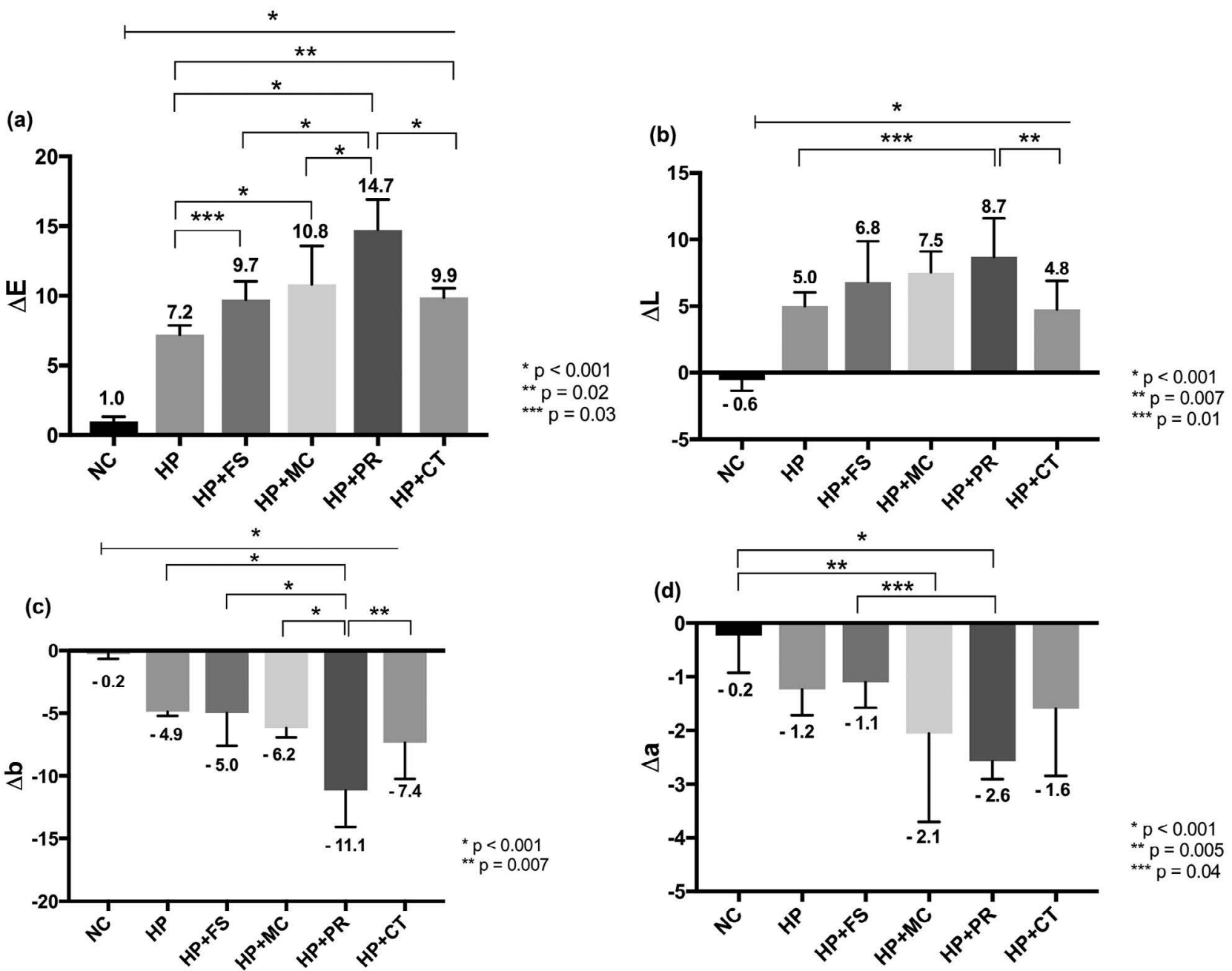

Figure 3- (a), (b), (c) and (d) Bar graph of mean (standard deviation) of $\Delta \mathrm{E}, \Delta \mathrm{L}, \Delta \mathrm{b}$, and $\Delta$ a values, respectively, for color alteration assay $\left(C I E L^{*} a^{*} b^{*}\right)$. Numbers are mean delta for each group. —demonstrates the comparison between groups from the start to end points under the line; - demonstrates the comparison between groups; asterisk indicates significant difference (one-way ANOVA/Tukey's test; $p<0.05$ )

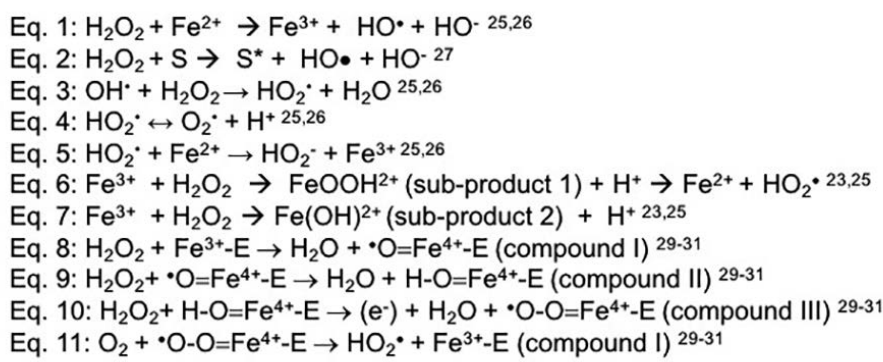

Figure 4- Degradation of $\mathrm{H}_{2} \mathrm{O}_{2}$ in the presence of chemical activators. Eq.=equation. $S=$ substrate. $S^{*}$ oxidized substrate. $E=e n z y m e$

structure and consequently the cytotoxicity with pulp cells, by increasing the reactivity of the product with dental structure after incorporating ferrous sulfate, manganese chloride, peroxidase, or catalase into a highly concentrated bleaching gel. We chose a $35 \% \mathrm{H}_{2} \mathrm{O}_{2}$ gel to evaluate the most challenging situation, since the indirect cytotoxicity of such dental products has been well-demonstrated in literature. ${ }^{6-10}$ The bleaching effectiveness was also assessed to demonstrate whether the chemical activators indeed increase the interaction of $\mathrm{H}_{2} \mathrm{O}_{2}$ with mineralized dental tissue. The null hypothesis of this study was partially rejected, since all chemical substances enhanced the esthetic outcomes, reduced residual $\mathrm{H}_{2} \mathrm{O}_{2}$ diffusion and oxidative stress generation compared with the HP group. However, cell viability reduction mediated by the $35 \% \mathrm{H}_{2} \mathrm{O}_{2}$ gel (HP group) was only significantly reduced by manganese chloride, peroxidase, and catalase.

Ferrous sulfate and manganese chloride were used 
to induce $\mathrm{H}_{2} \mathrm{O}_{2}$ catalysis with Fenton and Fenton-like reactions, respectively, in which the decomposition of $\mathrm{H}_{2} \mathrm{O}_{2}$ generates hydroxyl radicals ( $\left.\mathrm{HO}\right),{ }^{31-33}$ as shown in Figure 4 (Eq.1 and 2). In the presence of high concentrations of $\mathrm{H}_{2} \mathrm{O}_{2}, \mathrm{HO}$ interacts with excess $\mathrm{H}_{2} \mathrm{O}_{2}$ to promote a series of propagation reactions (Figure 4 , Eq. 3-5), resulting in the release of other free radicals, such as $\mathrm{HO}_{2} \cdot$ and $\mathrm{O}_{2} \cdot 31,32$

According to our results, ferrous sulfate reduced residual $\mathrm{H}_{2} \mathrm{O}_{2}$ diffusion by $21.5 \%$; yet it had insignificant effect on cell viability compared with HP group. On the other hand, manganese chloride reduced the residual $\mathrm{H}_{2} \mathrm{O}_{2}$ diffusion across enamel and dentin by $60.7 \%$, associated with substantial minimization in cell viability reduction promoted by HP group. These effects were related with increased reduction in oxidative stress generation by HP+MC group, compared with HP+FS. Both manganese chloride and ferrous sulfate enhanced considerably the DE values compared with plain $35 \%$ $\mathrm{H}_{2} \mathrm{O}_{2}$ gel. This result was corroborated by Duque, et al. ${ }^{29}$ (2014), who also observed adding ferrous sulfate to a commercial bleaching gel containing $35 \% \mathrm{H}_{2} \mathrm{O}_{2}$ enhanced the bleaching effectiveness; however, only an insignificant reduction in the trans-enamel and trans-dentinal cytotoxicity was observed. ${ }^{29}$ As shown in Figure 1, this chemical activator caused brown sub-product deposition, leading to $\mathrm{H}_{2} \mathrm{O}_{2}$ consumption with no release of free radicals, minimizing the effectiveness of the reaction. ${ }^{3,30}$ Reactions related to this process are demonstrated in Figure 4 (Eq. 6 and 7). Therefore, formation of these sub-products may be considered a disadvantage of the iron-based Fenton reaction.

We also observed a slight deposition of brown sub-products during manganese chloride reaction with the bleaching gel, which disappeared at the end of the reaction (Figure 1). According to the literature, soluble manganese is a stoichiometrically efficient catalyst for the generation of hydroxyl radicals; however, depending on $\mathrm{pH}$ regime, an amorphous manganese oxide precipitate occurs. ${ }^{33}$ Nevertheless, this component is capable of catalyzing $\mathrm{H}_{2} \mathrm{O}_{2}$ to release $\mathrm{O}_{2}, \mathrm{HO}_{2}{ }^{\circ}$, and $\mathrm{H}^{+27}$. The advantage of using manganese instead of iron is based on the high redox potential of manganese, which makes this molecule more prone to react with $\mathrm{H}_{2} \mathrm{O}_{2} \cdot{ }^{32,33}$ Differently from iron, which dissociates into intermediates for electron exchanges during reaction with $\mathrm{H}_{2} \mathrm{O}_{2}$, manganese, in turn, makes the reaction more effective (Figure 4, Eq.
7). ${ }^{32}$ In previous studies, researchers demonstrated that manganese gluconate/chloride increases the bleaching efficacy of $\mathrm{H}_{2} \mathrm{O}_{2}$ by around 1.5-8 times. ${ }^{24-26}$ Additionally, it was shown that the concentration of $\mathrm{H}_{2} \mathrm{O}_{2}$ and the time for diffusion through enamel and dentin are significantly reduced in the presence of manganese-containing activators, ${ }^{24,28}$ such as it was observed in this investigation.

Addition of peroxidase or catalase to the $35 \%$ $\mathrm{H}_{2} \mathrm{O}_{2}$ gel also had a positive effect on biologic and esthetic features. Both enzymes minimized the cell viability reduction, oxidative stress generation, and residual $\mathrm{H}_{2} \mathrm{O}_{2}$ diffusion, as well as increased the $D E$ values compared with those of the HP control group. These molecules comprise a group of enzymes called oxidoreductases, which contain an active metallic center in $\mathrm{Fe}^{3+}$ resting state. They are found on living tissues and act to scavenge the $\mathrm{H}_{2} \mathrm{O}_{2}$ arising from the respiratory chain and oxidative stress. ${ }^{34}$ Conversion of $\mathrm{H}_{2} \mathrm{O}_{2}$ into $\mathrm{H}_{2} \mathrm{O}$ and $\mathrm{O}_{2}$ by these enzymes involves two well-understood one-electron reduction steps, called peroxidase cycle. The $\mathrm{Fe}^{+3}$ metallic center of catalase and peroxidase reduces one molecule of $\mathrm{H}_{2} \mathrm{O}_{2}$ into $\mathrm{H}_{2} \mathrm{O}$, generating a covalent $\mathrm{Fe}^{+4} \mathrm{O}$ oxyferryl species, referred to as compound $\mathrm{I}$, which is two oxidizing equivalents above the resting state. When this intermediate reaction oxidizes a second $\mathrm{H}_{2} \mathrm{O}_{2}$ molecule, $\mathrm{O}_{2}$ and $\mathrm{H}_{2} \mathrm{O}$ are formed, generating a second intermediate enzyme, compound II, which is one oxidizing equivalent above the resting state. The second one-electron reduction step returns compound II to the resting state of the enzyme. Both compounds I and II are powerful oxidants, with redox potentials estimated to be close to $+1 \mathrm{~V}^{35-37}$ (Figure 4, Eq. 8 and 9 ). An oxidase cycle has been demonstrated by Berglund, et al. ${ }^{36}$ (2002) for horseradish peroxidase in the presence of excess $\mathrm{H}_{2} \mathrm{O}_{2}$. According to the author, compound II may be transformed into several oxidative species when in contact with $\mathrm{H}_{2} \mathrm{O}_{2}$, leading to the release of $\mathrm{HO}_{2}$ species (Figure 4, Eq. 10 and 11). Therefore, the suggestion is that peroxidase and catalase induced the formation of highly oxidative intermediates when added to the $35 \% \mathrm{H}_{2} \mathrm{O}_{2}$ bleaching gel, increasing the oxidative potential of the product. Gopinath, et al. ${ }^{27}$ (2013) demonstrated that $10 \%$ and $35 \% \mathrm{H}_{2} \mathrm{O}_{2}$ gels reached the same bleaching outcome in the presence of a natural extract rich in catalase and peroxidase, regardless of the $\mathrm{H}_{2} \mathrm{O}_{2}$ concentration. Travassos, et al. ${ }^{25}$ (2010) observed a $42.1 \%$ increase 
in bleaching effectiveness (DE) for a $35 \% \mathrm{H}_{2} \mathrm{O}_{2}$ gel after one single $3 \times 10$-minute tooth-whitening session when a peroxidase-rich extract was incorporated into the dental product. The authors speculated that this positive effect was related to the enhanced free radical formation mediated by this enzyme.

Overall, the indication is that the release of free radicals mediated by the interaction of $\mathrm{H}_{2} \mathrm{O}_{2}$ with chemical activators increase bleaching effectiveness, minimizing the amount of residual $\mathrm{H}_{2} \mathrm{O}_{2}$ that diffuse through enamel/dentin to cause toxic effects to the cultured pulp cells. However, one important limitation of this study is that free radicals released from the bleaching gels and their trans-enamel and trans-dentinal diffusion were ignored. Therefore, the cytotoxicity observed here for all chemically activated groups may also be related to the release of such reactive molecules capable of diffusing through enamel/dentin to reach the cells. This effect may be related to the contradictory results found for $\mathrm{H}_{2} \mathrm{O}_{2}$ diffusion on $\mathrm{HP}+\mathrm{MC}$ group. Instead of achieving the lowest $\mathrm{H}_{2} \mathrm{O}_{2}$ diffusion, this group had the same behavior as HP+FS and HP+CT groups for all the other parameters tested. We believe that manganese chloride increases the formation of free radicals in comparison with ferrous sulfate and catalase, but these free radicals may have diffused through enamel and dentin to play a role in the cytotoxicity to the pulp cells.

On the other hand, peroxidase also had the lowest amount of residual $\mathrm{H}_{2} \mathrm{O}_{2}$, which was statistically similar to manganese chloride. Nevertheless, the better cell parameters and whitening outcome found for HP+PR group compared with $\mathrm{HP}+\mathrm{MC}$ may result from the oxidase cycle reaction, since the reactive species described as compound I and III may have played a role in the reaction of $\mathrm{H}_{2} \mathrm{O}_{2}$ with tooth structure, resulting in a lower amount of free radical diffusion through enamel/dentin discs. Therefore, more studies are needed to demonstrate the pathway related to the minimization of the toxicity mediated by the chemical activators tested here. Non-stained discs were used in the biological assays to avoid the release of toxic components of black tea to the cells, as performed before. ${ }^{7,10,23,29}$ Since free radicals released by the bleaching gel were expected to react with the chromophores, we may speculate that a high amount of non-reacted molecules may have diffused to cause the toxic effects observed in this investigation. Also, several other relevant biological factors found in vivo, such as the presence of pulp pressure, extracellular matrix, and host immune cells, have been rejected in laboratorial tests to assess the biological and esthetic behavior of dental products. ${ }^{18}$ Hence, the results found in this in vitro study can be considered overestimated.

Torres, et al. ${ }^{28}$ (2013) reported that the use of chemical activators to minimize the residual $\mathrm{H}_{2} \mathrm{O}_{2}$ diffusion to the pulp chamber seems to be more evident when low-concentration bleaching gels are used. According to those authors, 35\% $\mathrm{H}_{2} \mathrm{O}_{2}$ formulations provide greater availability of residual $\mathrm{H}_{2} \mathrm{O}_{2}$, so, likely, the chemical activator is unable to reduce the rate of peroxide diffusion at secure levels. The literature has already shown that highconcentrated bleaching gels have intense potential to bleach teeth from the first 45 -minute session. ${ }^{16,17}$ Nevertheless, the increase in bleaching effectiveness demonstrated in this study may be useful to fasten the whitening outcome on dark-colored teeth, such as tetracycline stained teeth; however, more studies are needed to prove the effectiveness of the formulations tested in these specific situations.

The focus of the current studies is to reduce the concentration of in-office bleaching gels to minimize the negative effects on pulp cells. ${ }^{38,39}$ It has been previously demonstrated that a $50 \%$ reduction in the concentration of peroxide in bleaching gels with $35 \%$ $\mathrm{H}_{2} \mathrm{O}_{2}$ results in a significant positive effect on cell viability; but the bleaching effectiveness is harmed. 7,23 Therefore, since the manganese chloride, catalase, and peroxidase were capable of minimizing the cytotoxicity of a highly concentrated bleaching gel by increasing its reactivity with tooth structure, it seems reasonable that they may be considered a promising alternative to improve the biocompatibility and esthetic outcomes of low-concentrated whitening products. However, considering the limitations of this in vitro study, further investigations are needed to clarify the benefits of chemical activations to commercial bleaching agents and their safety for clinical applications. Also, a costbenefit analysis should be performed, since the purified horseradish peroxidase enzyme used here has a high cost. Evaluating other sources of this enzyme and performing dose-response studies may clarify the benefits of this substance as a chemical activator of tooth bleaching products. 


\section{Conclusion}

Chemical activation of $35 \% \mathrm{H}_{2} \mathrm{O}_{2}$ bleaching gel with manganese chloride, peroxidase, or catalase enhances tooth-whitening and reduces the amount of residual $\mathrm{H}_{2} \mathrm{O}_{2}$ capable of diffusing through enamel and dentin, minimizing the toxic effects of this product to pulp cells. Enzymatic activation with peroxidase featured the best biological and esthetic results compared with those of the other chemical activators.

\section{Acknowledgments}

This study was supported by the São Paulo Research Foundation - FAPESP (grant \# 2015/21770-4) and by the National Council for Scientific and Technological Development - CNPq (grants \#303599/2014-6 and 442336/2014-4).

\section{References}

1- Joiner A, Luo W. Tooth colour and whiteness: a review. J Dent. 2017;67S:S3-10.

2- Young N, Fairley P, Mohan V, Jumeaux C. A study of hydrogen peroxide chemistry and photochemistry in tea stain solution with relevance to clinical tooth whitening. J Dent. 2012;2:e11-6.

3- Suty H, De Traversay C, Cost M. Applications of advanced oxidation processes: present and future. Water Sci Technol. 2004;49(4):227-33. 4- Kwon SR, Li Y, Oyoyo U, Aprecio RM. Dynamic model of hydrogen peroxide diffusion kinetics into the pulp cavity. J Contemp Dent Pract. 2012;13(4):440-5.

5- Llena C, Forner L, Vazquez M. Hydrogen peroxide diffusion with and without light activation. Int J Esthet Dent. 2016;11(3):430-41. 6- Soares DG, Ribeiro AP, Silveira Vargas F, Hebling J, Souza Costa CA. Efficacy and cytotoxicity of a bleaching gel after short application times on dental enamel. Clin Oral Investig. 2013;17(8):1901-9.

7- Soares DG, Basso FG, Hebling J, Souza Costa CA. Concentrations of and application protocols for hydrogen peroxide bleaching gels: effects on pulp cell viability and whitening efficacy. J Dent. 2014;42(2):185-98. 8- Soares DG, Basso FG, Scheffel DS, Hebling J, Souza Costa CA. Responses of human dental pulp cells after application of a low-concentration bleaching gel to enamel. Arch Oral Biol. 2015;60(9):1428-36.

9- Soares DG, Basso FG, Hebling J, Souza Costa CA. Immediate and late analysis of dental pulp stem cells viability after indirect exposition to alternative in-office bleaching strategies. Clin Oral Investig. 2015;19(5):1013-20.

10- Oliveira Duque CC, Soares DG, Basso FG, Hebling J, Souza Costa CA. Influence of enamel/dentin thickness on the toxic and esthetic effects of experimental in-office bleaching protocols. Clin Oral Investig. 2017;21(8):2509-20.

11- Llena C, Collado-González M, Tomás-Catalá CJ, García-Bernal D, Oñate-Sánchez RE, Rodríguez-Lozano FJ, et al. Human dental pulp stem cells exhibit different biological behaviours in response to commercial bleaching products. Materials (Basel). 2018;11(7). pii: E1098.

12- Cintra LT, Benetti F, Silva Facundo AC, Ferreira LL, Gomes-Filho $J E$, Ervolino $E$, et al. The number of bleaching sessions influences pulp tissue damage in rat teeth. J Endod. 2013;39(12):1576-80.
13- Benetti F, Gomes-Filho JE, Ferreira LL, Ervolino E, Briso AL, SivieriAraújo $G$, et al. Hydrogen peroxide induces cell proliferation and apoptosis in pulp of rats after dental bleaching in vivo: effects of the dental bleaching in pulp. Arch Oral Biol. 2017;81:103-9.

14- Silva-Costa RS, Ribeiro AE, Assunção IV, Araújo Júnior RF, Araújo AA, Guerra GC, et al. In-office tooth bleaching with $38 \%$ hydrogen peroxide promotes moderate/severe pulp inflammation and production of II- $1 \beta$, TNF- $\beta$, GPX, FGF-2 and osteocalcin in rats. J Appl Oral Sci. 2018;26:e20170367.

15- Benetti F, Gomes-Filho JE, Ferreira LL, Sivieri-Araújo G, Ervolino E, Briso $A L$, et al. Concentration-dependent effect of bleaching agents on the immunolabelling of interleukin-6, interleukin-17 and CD5-positive cells in the dental pulp. Int Endod J. 2018;51(7):789-99.

16- He LB, Shao MY, Tan K, Xu X, Li LY. The effects of light on bleaching and tooth sensitivity during in-office vital bleaching: a systematic review and meta-analysis. J Dent. 2012;40(8):644-53.

17- Reis A, Kossatz S, Martins GC, Loguercio AD. Efficacy of and effect on tooth sensitivity of in-office bleaching gel concentrations: a randomized clinical trial. Oper Dent. 2013;38(4):386-93.

18- Soares DG, Hebling J, de Souza Costa CA. Tooth whitening. In: Perdigão J, editor. Human pulpal responses to peroxides. $1 .^{\mathrm{t}}$ ed. Springer: Switzerland; 2016. p. 81-97.

19- Souza Costa CA, Riehl H, Kina JF, Sacono NT, Hebling J. Human pulp responses to in-office tooth bleaching. Oral Surg Oral Med Oral Pathol Oral Radiol Endod. 2010;109(4):59-64

20- Roderjan DA, Stanislawczuk R, Hebling J, Souza Costa CA, Soares DG, Reis A, et al. Histopathological features of dental pulp tissue from bleached mandibular incisors. J Mater Sci Engin B. 2014;4:178-85.

21- Roderjan DA, Stanislawczuk R, Hebling J, Souza Costa CA, Reis A, Loguercio AD. Response of human pulps to different in-office bleaching techniques: preliminary findings. Braz Dent J. 2015;26(3):242-8.

22- Soares DG, Marcomini N, Basso FG, Pansani TN, Hebling J, Souza Costa CA. Indirect cytocompatibility of a low-concentration hydrogen peroxide bleaching gel to odontoblast-like cells. Int Endod J. $2016 ; 49(1): 26-36$.

23- Soares DG, Basso FG, Pontes EC, Garcia LF, Hebling J, Souza Costa CA. Effective tooth-bleaching protocols capable of reducing $\mathrm{H}_{2} \mathrm{O}_{2}$ diffusion through enamel and dentine. J Dent. 2014;42(3):351-8.

24- Torres $C R$, Wiegand $A$, Sener $B$, Attin T. Influence of chemical activation of a $35 \%$ hydrogen peroxide bleaching gel on its penetration and efficacy - in vitro study. J Dent. 2010;38(10):838-46.

25- Travassos AC, Rocha Gomes Torres C, Borges AB, Barcellos DC. In vitro assessment of chemical activation efficiency during in-office dental bleaching. Oper Dent. 2010;35(3):287-94.

26- Batista GR, Barcellos DC, Torres CR, Goto EH, Pucci CR, Borges $A B$. The influence of chemical activation on tooth bleaching using $10 \%$ carbamide peroxide. Oper Dent. 2011;36(2):162-8.

27- Gopinath S, James V, Vidhya S, Karthikeyan K, Kavitha S, Mahalaxmi S. Effect of bleaching with two different concentrations of hydrogen peroxide containing sweet potato extract as an additive on human enamel: an in vitro spectrophotometric and scanning electron microscopy analysis. J Conserv Dent. 2013;16(1):45-9.

28- Torres CR, Souza CS, Borges AB, Huhtala MF, Caneppele TM. Influence of concentration and activation on hydrogen peroxide diffusion through dental tissues in vitro. Scientific World Journal. 2013;2013:193241.

29- Duque CC, Soares DG, Basso FG, Hebling J, Souza Costa CA. Bleaching effectiveness, hydrogen peroxide diffusion, and cytotoxicity of a chemically activated bleaching gel. Clin Oral Investig. 2014;18(6):1631-7.

30- Chen JH, Xu JW, Shing CX. Decomposition rate of hydrogen peroxide bleaching agents under various chemical and physical conditions. J Prosthet Dent. 1993;69(1):46-8. 
31- Hanna K, Kone T, Ruby C. Fenton-like oxidation and mineralization of phenol using synthetic Fe(II)-Fe(III) green rusts. Environ Sci Pollut Res Int. 2010;17(1):124-34

32- van Genuchten CM, Peña J. Mn(II) oxidation in Fenton and Fenton type systems: identification of reaction efficiency and reaction products. Environ Sci Technol. 2017;51(5):2982-91.

33- Watts RJ, Sarasa J, Loge FJ, Teel AL. Oxidative and reductive pathways in manganese-catalyzed Fenton's reactions. J Environ Eng. 2005; 131:158-64.

34- Heck DE, Shakarjian M, Kim HD, Laskin JD, Vetrano AM. Mechanisms of oxidant generation by catalase. Ann N Y Acad Sci. 2010;1203:120-5. 35- Hernández-Ruiz J, Arnao MB, Hiner AN, García-Cánovas F, Acosta M. Catalase-like activity of horseradish peroxidase: relationship to enzyme inactivation by $\mathrm{H}_{2} \mathrm{O}_{2}$. Biochem J. 2001;354(Pt 1):107-14.
36- Berglund GI, Carlsson GH, Smith AT, Szöke H, Henriksen A, Hajdu J. The catalytic pathway of horseradish peroxidase at high resolution. Nature. 2002;417(6887):463-8.

37- Zámocký M, Hofbauer S, Schaffner I, Gasselhuber B, Nicolussi $A$, Soudi $M$, et al. Independent evolution of four heme peroxidase superfamilies. Arch Biochem Biophys. 2015;574:108-19.

38- Ferraz NK, Nogueira LC, Neiva IM, Ferreira RC, Moreira AN, Magalhães CS. Longevity, effectiveness, safety, and impact on quality of life of low-concentration hydrogen peroxides in-office bleaching: a randomized clinical trial. Clin Oral Investig. 2018. doi: 10.1007/ s00784-018-2607-7. Epub ahead of print.

39- Bersezio C, Martín J, Angel P, Bottner J, Godoy I, Avalos F, et al. Teeth whitening with $6 \%$ hydrogen peroxide and its impact on quality of life: 2 years of follow-up. Odontology. 2019;107(1):118-25. 